\title{
Adaptive Switching Algorithm for Shunt Active Power filter with Model Predictive Control
}

\author{
Akram ElHelbawy, Mostafa S. Hamad, Eman Hamdan and Hussien Desouki \\ Arab Academy for Science Technology \& Maritime Transport (AASTMT), Alexandria, Egypt
}

\begin{abstract}
The Algorithmic controllers have been widely adopted for power converter applications as in Model Predictive control and adaptive control. Algorithmic controllers are usually functioning with restrictions for electronic component protection. This article presents algorithmic control for modulating the switching frequency of power converters to reduce both switching losses and switching frequency. A low volt converter for shunt active power filter is used as an application for showing the effect of adaptive switching. Least Mean Square Adaptive Linear Neuron (ADALINE LMS) is proposed as algorithmic adaptive switching for model predictive controllers used with power converter applications. The proposed technique shows the reliability of limiting the switching frequency, interfacing it with model predictive control. The new technique is applicable on electrical grid and aircraft applications. THD is kept within a stable acceptable limit $<5 \%$ with less switching frequency. The technique is designed and simulated on MATLAB SIMULINK and results are verified.
\end{abstract}

Keywords: Power Converters; MPC; SAPF; Adaptive control ADALINE; switching frequency reduction

\section{Introduction}

Due to the high-performance demands required by different power applications specifically in harmonic elimination, datacentres, and CPUs, systems are operating with high switching frequencies and the inverters incur high switching losses, resulting in higher cooling requirements and reduced efficiency. Switching frequency reduction became the main issue to reach the best system performance with less cost. Various electronic components are manufactured to cover wide range of switching frequencies for different requirements, but low volt power converters applications are still in need of a reliable solution to control both performances, EMI mitigation, and decrease the cost. Conventional techniques based on PWMhard switching were used as the main approach to control the switching of power converter which showed high switching losses and low performance of output signal. Many references discussed PWM techniques and their effects on power consumption [1-3].

In this article, harmonic elimination is the main application of power converters. Shunt Active Power Filter started to play an effective role in enhancing the power factor. It has a dynamic behaviour compared to other filtering techniques. Since it is operating with an MPC controller, APF becomes more reliable compared to passive filters [4-5]. Several references talked about SAPF techniques as three-phase and using the park - Clark transformation [6-11].

SAPF with PWM and a carrier signal creates sideband harmonics over a wide frequency range around the multiple carrier-frequency harmonics, and these can encroach into the low frequency range. This issue is particularly critical when low carrier - fundamental frequency 
ratios are used such as in aerospace applications, where high fundamental frequencies exist. As a result, a three-phase active shunt filter with a adaptive switching frequency was proposed to mitigate any resulted side band harmonics [14].

SAPF harmonic elimination technique can be controlled using PI controller, MPC, or adaptive controllers [6-13]. Algorithmic controllers are more reliable with better response than PI due to setpoint change in additional to multivariable control nature. They are able avoid using PWM technique in addition to their reliability in modifying. In this article, SAPF is used with a three-phase power converter controlled with FCS-MPC as an application for adaptive switching using adaptive linear neurons (ADALINE). Coordination between ADALINE and FCS-MPC for switching frequency tuning is highlighted.

In SAPF application, the accuracy of the reference signal determines the stability of the whole system, therefore, it is important to ensure having a robust system for harmonic extraction. Most of the inaccuracy and instability of the output signals resulting from MPC is due to a weak reference signal which misleads the performance of MPC and the whole system. ADALINE is the best independent digital filter on which MPC can rely on. In this paper, the ADALINE LMS technique is used to extract the exact needed harmonic signal for MPC utilizing its learning factor with iterations for reaching the needed reference signal [12].

The model is represented using park transformation for the conversion of a three-phase frame to a two- dynamic phase frame. It is supported with PLL to synchronize the whole system

\section{ADALINE LMS}

The adaptive Neuron Least Mean Square technique is originally taken from living organic neurons. ADALINE is considered the preferred filter for high dynamics due to its algorithmic nature. Its output is not prone to systems lag as in other conventional types of filters.

In the ADALINE technique, there are input arrays, there may be a favored reaction wherein the neuron is knowledgeable about the output goal concerning the stated input array.

The output is in comparison with the desired signal to get the error that's used in adapting the weights (represented by using arrows on weights). The goal of modifying the weights is to limit the mean rectangular of the error averaged over all schooling patterns (inputs) now not best one enter as shown in fig (1).

Input pattern: $\mathrm{X}_{1}, \mathrm{X}_{2}, \ldots, \mathrm{X}_{\mathrm{n}},--$ Weight's sum: $\mathrm{Y}_{\mathrm{k}}$. 


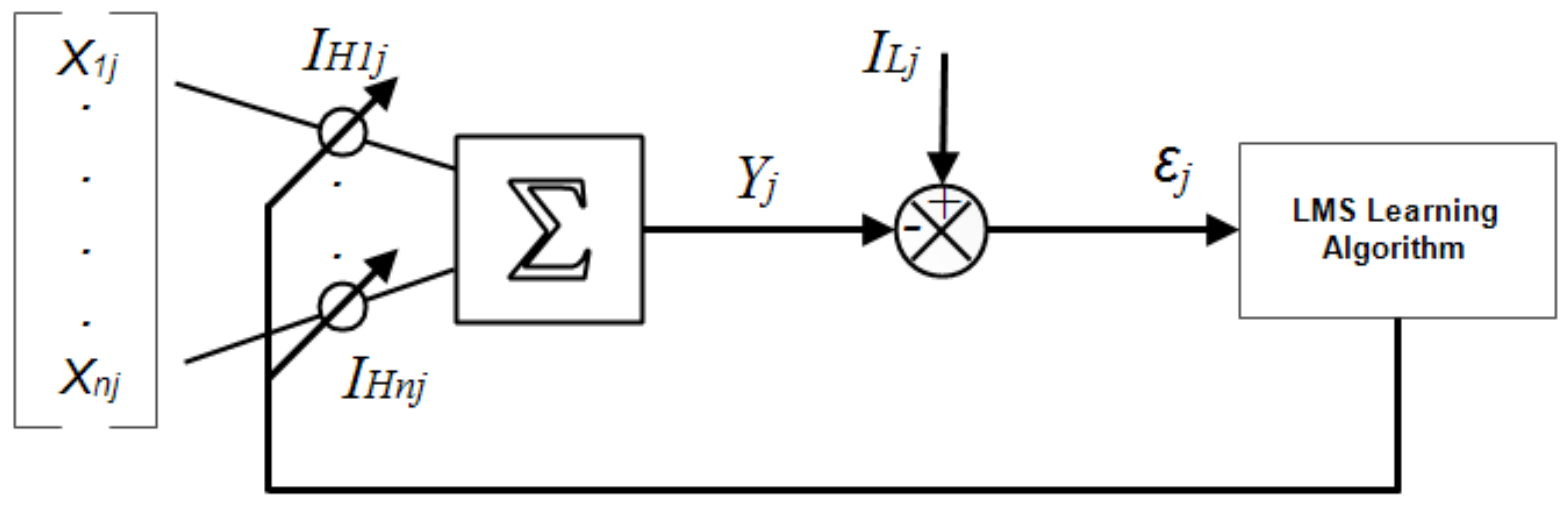

Figure 1: ADALINE linear neuron

In this article, the ADALINE LMS method applied for extraction the handiest and robust harmonic signal out of the whole load current signal and use it is referred to as finite control set model predictive control system modeling.

For Harmonic representations:

$$
\mathrm{X}_{(1 . . n) j}=\left[\sin \left(\mathrm{h}_{\mathrm{i}} * \omega\right) \cos \left(\mathrm{h}_{\mathrm{i}} * \omega\right)\right]
$$

$h_{i}$ : The chosen harmonic order. The weight summation:

$$
\mathrm{Y}_{\mathrm{j}}(\mathrm{k})=\sum_{\mathrm{i}}^{\mathrm{N}}\left(\mathrm{X}_{(1 . . n) j}{ }^{\mathrm{T}} * \mathrm{I}_{\mathrm{H}(1 . \mathrm{n}) \mathrm{j}}(\mathrm{k})\right)
$$

For conditioning ADALINE, several assumptions took place. Input patterns are conditioned to be system harmonics starting from third harmonic up to thirteenth order harmonic. The more harmonics assumed, the more accurate reference signal generated from ADALINE.

The error of Adaline is taken into consideration as the difference between the output signal and the desired signal (represented as the load current). The error signal is used with the learning factor (assumed to be as small as possible) and gets iterated to enhance the weight factor.

Error signal equation:

$$
\varepsilon_{j}(\mathrm{k})=\mathrm{I}_{L j}(k)-\mathrm{Y}_{\mathrm{j}}(\mathrm{k})
$$

Adaptive equation:

$$
\mathrm{I}_{\mathrm{H}(1 . \mathrm{n})}(\mathrm{k}+1)=\mathrm{I}_{\mathrm{H}(1 . \mathrm{n}) \mathrm{j}}(\mathrm{k})+2 \mu * \varepsilon_{j}(\mathrm{k}) * \mathrm{X}_{(1 . . n) j}
$$

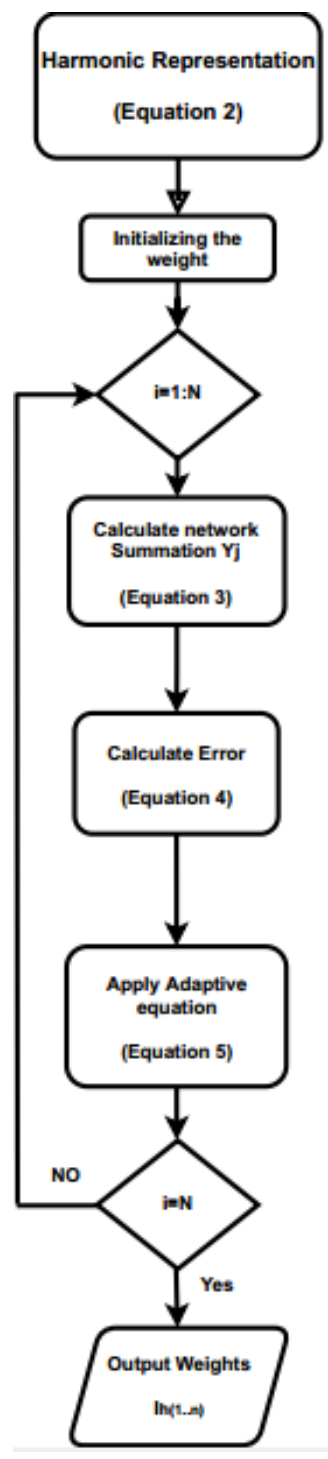

Figure 2: Flow chart ADALINE algorithm. 
$\mathrm{I}_{\mathrm{H}(1 . . n) \mathrm{j}}$ : Trained Harmonic current.

$2 \mu$ : learning factor

Although that ADALINE is a real-time system its iterations increase the calculation time which should be taken into consideration in different practices. Fig (2) represents the followed algorithm sequence including iteration for minimizing the error to its minimum possible level.

\section{Modeling of Shunt Active Power Filter}

Shunt Active power filter general schematic drawing is shown in fig. (3)

Application values:

$I_{\mathrm{Lj}}$ : Load Current where j: a,b,c.

The source current $\left(\mathrm{I}_{\mathrm{s}}\right)$ is nearly quasi-square waveform due to the nonlinear load with rectifier existence. While the fundamental signal is given in equation (6).

$$
\mathrm{I}_{\mathrm{Lj}}=\mathrm{I}_{\mathrm{Sj}} * 1.05
$$

The rating current of the shunt active power filter is expressed as

$$
I_{f j}=\sqrt{I_{S j}^{2}-I_{S j 1}^{2}}
$$

$I_{S j 1}$ : Fundamental Signal.

APF power rating can be represented as:

$$
\mathrm{S}=3 \mathrm{~V}_{\mathrm{s}}{ }^{*} I_{f} j
$$

The DC link voltage of Shunt Active Power filter:

$$
V_{d c}=2 * V_{p c c j} \text { OR }=2 \sqrt{2} * V_{S}
$$

In this article the energy rule is used for calculating capacitance value:

$$
\Delta E=\frac{1}{2} * C_{d c} *\left(V_{d c}-V_{d c}^{* 2}\right)=3 * V s * k * I_{f j} * \Delta t
$$

Following the mentioned calculation support the harmonic elimination technique with a better power factor [15].

In figure (3), the voltage of point of common coupling (Vpcc):

$$
\mathrm{V}_{\mathrm{pcc} j \mathrm{j}}=\left[\mathrm{V}_{\mathrm{pcc} \text { a }} \mathrm{V}_{\mathrm{pcc} \text { b }} \mathrm{V}_{\mathrm{pcc} \mathrm{c}}\right]
$$

Applying KVL for the three-phase:

$$
V_{p c c j}(\mathrm{t})=L f \frac{d I_{f j}}{d t}+R f * I_{f j}(\mathrm{t})+V_{d M}+V M N
$$

As mentioned in [16] equation (13) represents the voltage difference between point $\mathrm{M}$ (Shown in fig (3)) and point N (reference point inside the converter block) 


$$
V M N=-\frac{1}{3}+\sum_{m=1}^{3} v m M
$$

In the three-phase inverter, the upper switches are only controlled since the lower is always at the opposite state compared to the upper ones.

$$
V_{d M}=g_{d M} * V d c
$$

$g_{d M}=g 1, g 2, g 3$ : represent the upper switching gates.

After substituting (13)-(14) in (12)

$$
\frac{d I_{f j}}{d t}=-\frac{R f}{L f} * I_{f j}(t)+\frac{V_{p c c j}(t)}{L f}-\frac{V d c}{L f}\left(G_{d}-\frac{1}{3} \sum_{m=1}^{3} g m\right)
$$

Where $\mathrm{d}=1,2,3$.

To model the system in MPC, it is important to have it in linearized discretized state-space form, as given by:

$$
\frac{d I_{f j}}{d t}=\left(-\frac{R f}{L f} * I_{f j}(t)\right)+\frac{1}{L f} *\left(V_{p c c j}(t)-V d c * d_{d}\right)
$$

Equation (16) is in continuous form, it needs to be in the discretized state-space form:

$$
I_{f j}(k)=\left(1-\frac{R f * T s}{L f}\right) * I_{f j}(k-1)+\frac{T s}{L f} *\left(V_{p c c j}(k-1)-V d c * d_{d}\right)
$$

Ts: Sampling time

Equation (17) is the system modeling that includes all the electrical components to be represented inside Model predictive control.

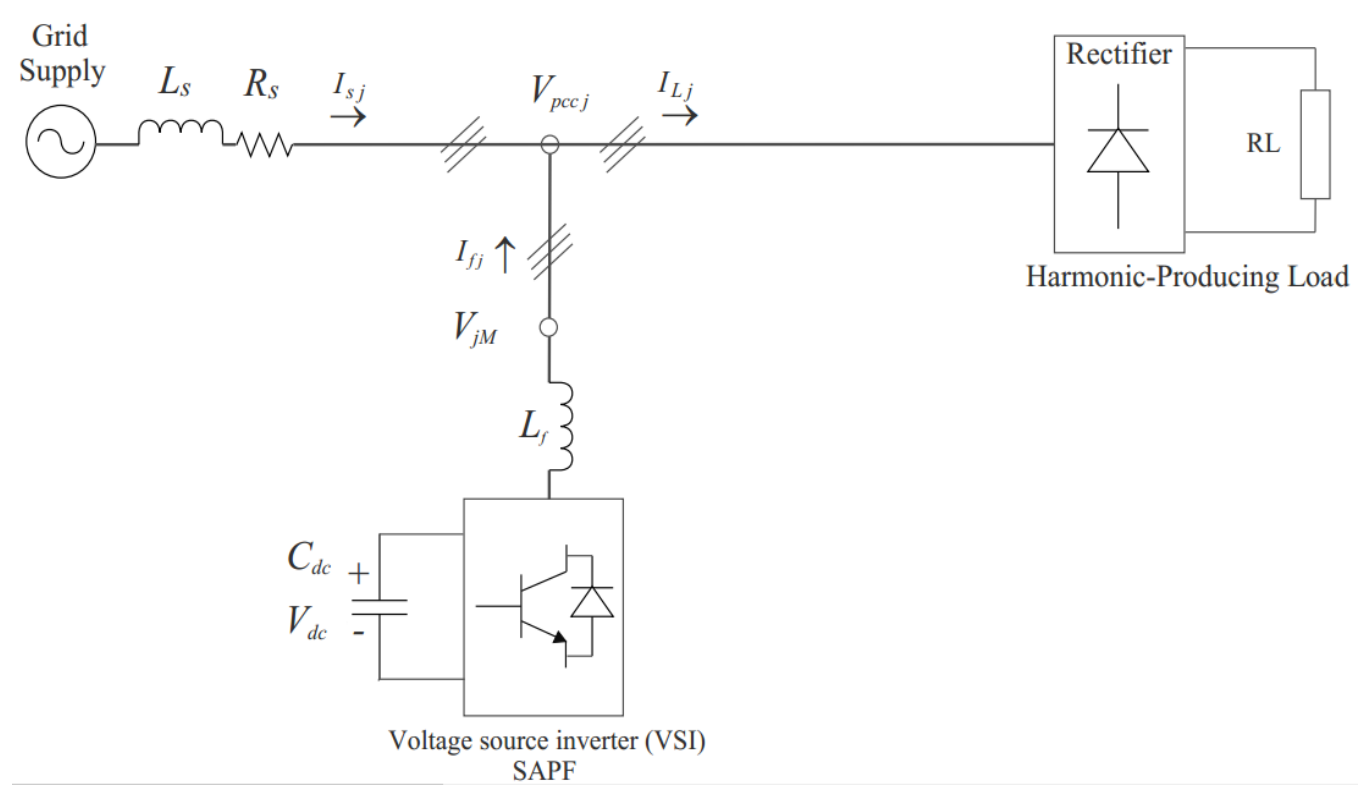

Figure 3: General Scheme for Shunt Active Power Filter Scheme 


\section{Model Predictive Control technique}

Recently, various model predictive control (MPC) techniques are used in many distinctive fields for robotics, industrial automation, chemical, and energy. Processors are developed and improved as a result, it was suitable to start thinking of integrating MPC with power electronics.

This article discusses one type of MPC which is suitable for the current application referred to (FCS-MPC).

The cost function is the base of the MPC control strategy which can handle nonlinearities and multivariable systems simultaneously in case they are modeled and specified correctly.

Model Predictive Control does not need any additional interface for controlling power converters. It is an algorithmic-

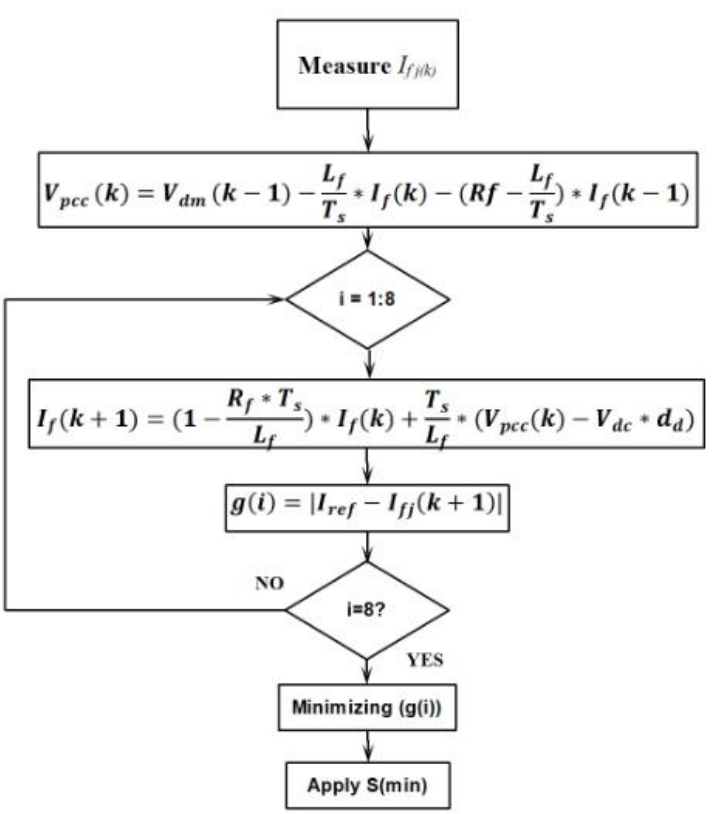

Figure 4: Flow chart of the whole prediction algorithm. based controller, as a result, gates can directly go to the switching elements. MPC allows additional system expansion.

In this paper, FCS MPC is used with a predicted discretized model of SAPF within a specific horizon. At each sampling time, the cost function is calculated considering the possible switching states to choose the optimum selection which provides the least cost this step is done by minimizing the results of the cost function to reach the result for triggering the inverter. The process of MPC is discussed in detail in [17-19].

Recalling equation (17) and converting it into prediction form with Forward Euler Method: ]]

$$
\begin{gathered}
I_{f j}(k)=\left(1-\frac{R f * T s}{L f}\right) * I_{f j}(k-1)+\frac{T s}{L f} *\left(V_{p c c j}(k-1)-V_{d c} * d_{d}\right) \\
I_{f j}(k+1)=\left(1-\frac{R f * T s}{L f}\right) * I_{f j}(k)+\frac{T s}{L f} *\left(V_{p c c j}(k)-V_{d c} * d_{d}\right)
\end{gathered}
$$

Following the control sequence as shown in Fig(4). The controller starts by taking the needed measures as the first step.

The second step is followed by calculating the voltage of the common coupling point of SAPF with the grid as shown in:

$$
V_{p c c}(k)=V_{d m}(k-1)-\frac{L f}{T s} * I_{f}(k)-\left(R f-\frac{L f}{T s}\right) * I_{f}(k-1)
$$




\section{$4^{\text {th }}$ International Conference on Modern Research in Science, Engineering and Technology}

The third step is performing the iterations within all the available switching states and calculating the predicted current as mentioned in equation (18).

In the fourth step, the cost function is calculated for every switching state as in equation (20).

The last step is mentioning which switching state has the least cost function to be triggered to the converter.

All the previous steps can be performed within (alfa - beta) or (dq) frame which will reflect on each step in the algorithm including the cost function by having both real and imaginary parts or dq form.

As shown previously, MPC is algorithmic control, and as a result switching frequency is dependent on sampling and calculation time of the algorithm which shows no constraints for limiting

or controlling the switching frequency. As a result, modifying the cost function is an essential step.

$$
\mathrm{g}(\mathrm{i})=\left|I_{\text {ref }}-I_{f j}(k+1)\right|
$$

$\mathrm{g}(\mathrm{i})$ : cost function, i: index of iterartion.

$I_{r e f}$ : the reference current from ADALINE LMS to MPC.

Figure (5) shows the whole cycle starting from the reference signal which is transferred from ADALINE LMS to MPC converting between the dq-alfaBeta transformation. The whole system is synchronized by Phase-Locked Loop (PLL). Then the output is directly connected to power converter switches.

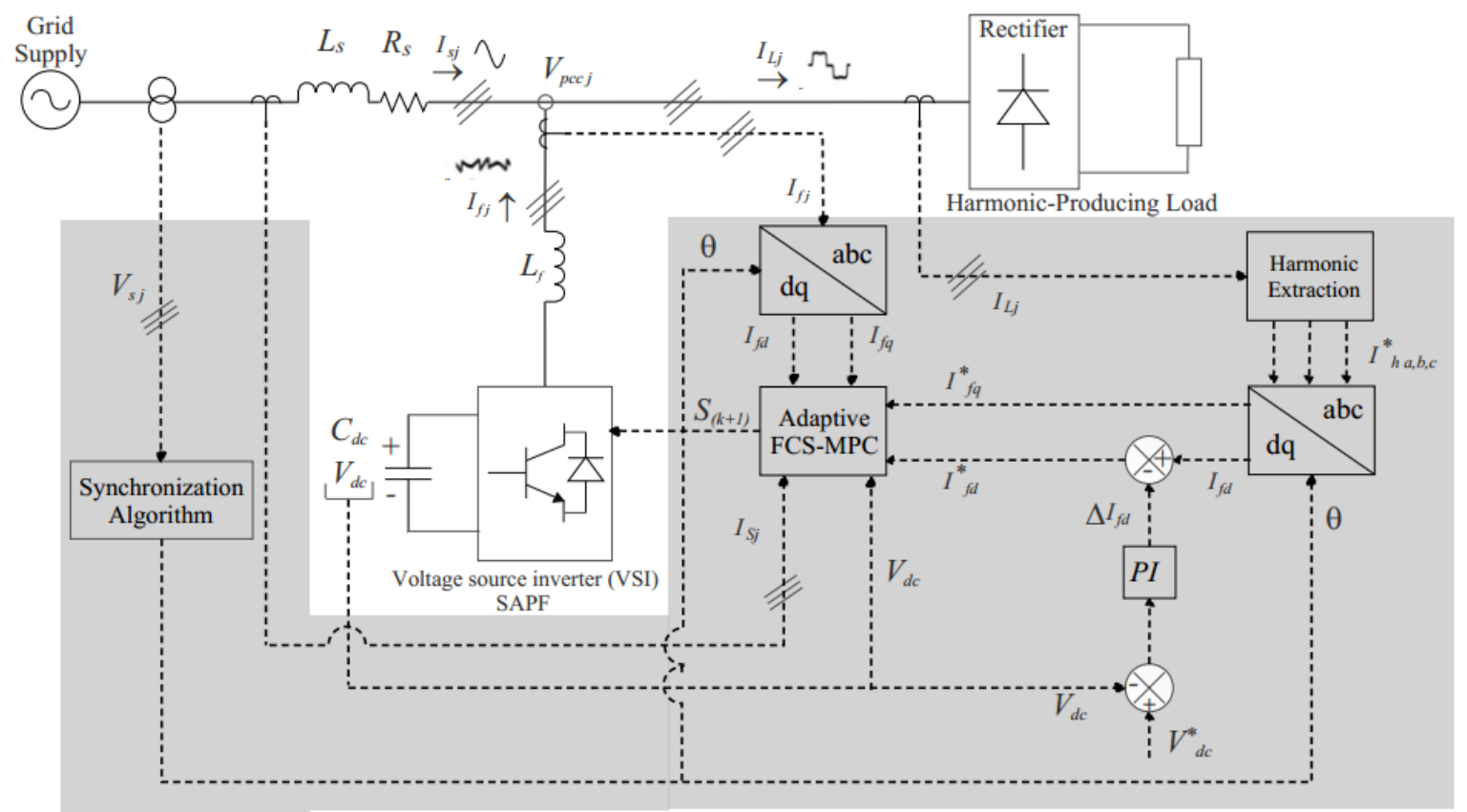

Figure 5: Represents a flow chart of the whole SAPF system with its controller. 


\section{Adaptive Switching using THD}

MPC is not relying on PWM or any carrier signal which makes the switching frequency uncontrollable. Relying on sub-modules number, in the case of Modular multilevel converter or relying only on the 6 switches in the conventional converter is not a reliable solution for controlling the switching frequency, as a result, a solution is needed for a reliable and robust solution for controlling switching frequency with minimum effect on the output signal quality. Few papers discussed the switching frequency problem and offered some solutions [20] for MMC. In this article, a novel algorithmic technique is shown for controlling switching frequency with a low effect of THD.

Since the objective is to maintain a low THD while having a low switching frequency, so it is important to specify a flexible range of THD for which the output signal can have a modulated variable output according to the switching frequency.

The mentioned modulated variable modifies the cost function in MPC. As a result, the cost function should change but the addition switching signal as a factor with weight in MPC's cost function. In this research, ADALINE is used as a generator of the adaptive weight factor of MPC for controlling the switching frequency portion of the cost function.

Fig (6) represents Adpaptive neuorn algorithmic sequence for generating the appropriate adaptive weight for MPC, where "THDup" is the maximum allowed value specified for THD.

$$
\mathrm{Y}(\mathrm{t})=\operatorname{THDr}(\mathrm{t})
$$

Where THDr is the initial value for THD.

$$
\begin{aligned}
& \varepsilon(\mathrm{t})=\mathrm{THD}(\mathrm{t})-\mathrm{Y}(\mathrm{t}) \\
& \mathrm{THD}=\frac{\sqrt{\sum_{\mathrm{i}=2}^{\mathrm{G}} \mathrm{M}_{\mathrm{i}}^{2}}}{\mathrm{M}_{1}}
\end{aligned}
$$

Where M is the RMS value of the ith harmonic order, M1 is the RMS of the fundamental signal.

$$
\mathrm{Sw}_{(\mathrm{j}+1)}=\mathrm{Sw}_{\mathrm{j}}+2 * \mu * \varepsilon_{\mathrm{j}} * \mathrm{THDr}_{\mathrm{j}}
$$

Equations (21) - (24) are the governing equations for adjusting the adaptive weighting factor of MPC. When the THD decreases to a low level, it is a good chance to allow the switching frequency to decrease to a certain acceptable level, meanwhile, it allows using higher sampling time, if the controller allows, maintaining the stability of the system.

Now the cost function of MPC is needed to be modified from equation (20) to be equation (25).

$$
\mathrm{g}(\mathrm{i})=\left|I_{\text {ref }}-I_{f j}(k+1)\right|+\mathrm{Sw}_{(\mathrm{j}+1)} *\left|\mathrm{~S}_{\mathrm{old}}-\mathrm{S}_{\text {new }}\right|
$$

Where $S_{\text {Old }}$ : Switching state in the previous iteration. $-S_{\text {new }}$ : Switching state in current Iteration.

It is important to note that both number of iteration and learning factor are effective parameters on adaptive neuron and as a result on switching frequency. 


\section{$4^{\text {th }}$ International Conference on Modern Research in Science, Engineering and Technology}

In some applications as aircraft, the fundamental frequency reaches $400 \mathrm{~Hz}$ in order to work with less size and less copper material and as a result less weight for aircraft purposes [21]. Here the adaptvie switching is efficient and has a notable role in reducing switching frequency of SAPF applications on aircraft.

\section{Results}

Table 1 shows the values applied with the designed model and simulation.

Table 1 The values used in the simulation

\begin{tabular}{|l|c|}
\hline $\mathrm{V}_{\mathrm{S}}$ (Grid voltage) & $\begin{array}{c}326.6 \mathrm{~V} \text { up to } \\
730 \mathrm{~V}\end{array}$ \\
\hline $\mathrm{L}_{\mathrm{f}}$ (Filter inductance) & $1 \mathrm{e}-3 \mathrm{H}$ \\
\hline $\mathrm{L}_{\mathrm{S}}$ (Source inductance) & $0.15 \mathrm{e}-3 \mathrm{H}$ \\
\hline $\mathrm{R}_{\mathrm{S}}$ (Source resistance) & $0.001 \mathrm{Ohm}$ \\
\hline $\mathrm{L}_{\mathrm{L}}$ (Load line inductance) & $10 \mathrm{e}-3 \mathrm{H}$ \\
\hline $\mathrm{R}_{\mathrm{L}}$ (Load line Resistance) & $0.1 \mathrm{Ohm}$ \\
\hline $\mathrm{T}_{\mathrm{S}}$ (Sampling time) & $2 \mathrm{e}-5 \mathrm{sec}$ \\
\hline Fundamental Frequency(f) & $50 \mathrm{~Hz}$ \\
\hline Average Switching Frequency $\left(\mathrm{F}_{\mathrm{sw}}\right)$ & $11 \mathrm{kHz}$ \\
\hline $\mathrm{S}$ (power) & $14 \mathrm{kVA}$ \\
\hline
\end{tabular}

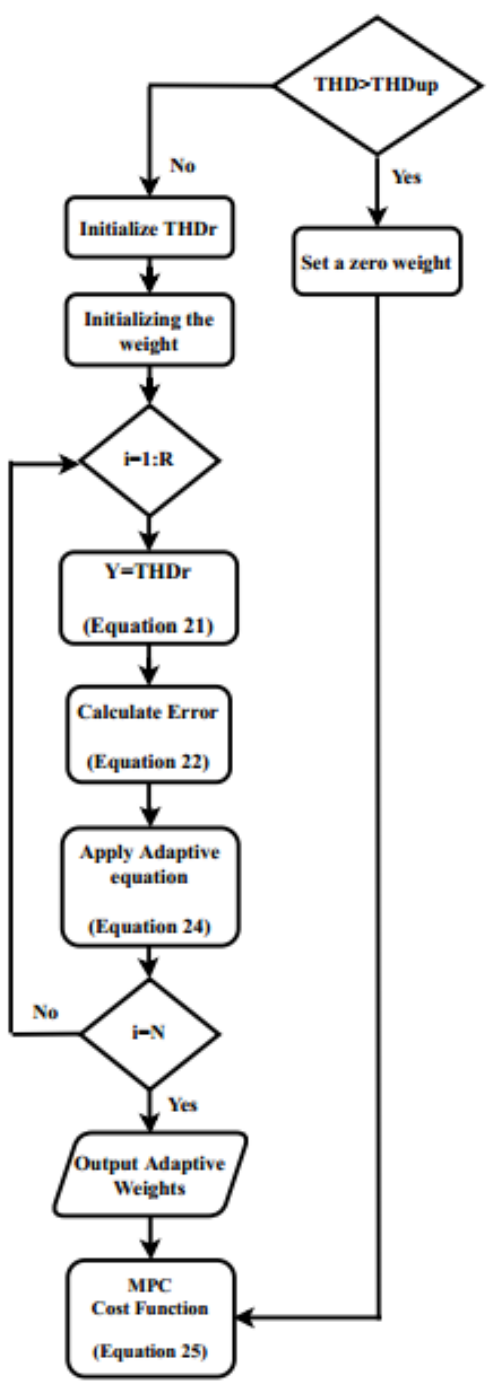

Fig. (7) shows the difference between the load and source signal after the filtering effect. THD

Figure 6: Adaptive neuron for switching frequency reaches $(25.44 \%)$ as shown in fig. (8) while after applying SAPF THD reaches $1.95 \%$, as shown in fig (10a), with (5th and 7th harmonics $<0.4 \%$ ). Fig. (7c) is the result of injection fig.(7b) in fig.(7a). Fourier analysis representation from the load current to be used as a reference signal for model predictive control is showed in fig.(7b).

Applying the adaptive switching technique has a low effect on the performance of SAPF. Power inverter switching frequency before applying the adaptive switching to be variable value around $(9.7 \mathrm{kHz})$ is shown in fig $(9 \mathrm{a})$. After applying adaptive switching technique, switching frequency values reache $(4 \mathrm{kHz})$ as shown in fig (9b) with THD (3.43\%) as shown in fig (10b). The mentioned adaptive switching technique not only reduces the switching frequency but also represents an algorithmic constraint that supports model predictive control for the robustness and stability of the system.

For aircraft applications where the fundamental frequency reaches $(400 \mathrm{~Hz}), \mathrm{SAPF}$ decreases the THD up to (2.91\%) as shown in fig. (12a) with switching frequency $(90 \mathrm{kHz})$ using higher sampling time (Ts=2e-6). After applying switching frequency on the same application, the switching frequency reaches $(19 \mathrm{kHz})$ as shown in fig. (11b) with THD increases up to $(3.81 \%)$ as in fig. (12b). The changes in the THD with switching frequency is affected by number of iterations, as well as, learning factor of adaptvie switching algorithm. 
$4^{\text {th }}$ International Conference on Modern Research in

Science, Engineering and Technology

The results shows $(58 \%)$ decrease, from $(9.7 \mathrm{kHz})$ to $(4 \mathrm{kHz})$, in switching frequency for 50 $\mathrm{Hz}$ fundamental frequency and $(78 \%)$, from $(90 \mathrm{kHz})$ to $(19 \mathrm{kHz})$, for $400 \mathrm{~Hz}$ fundamental frequency.
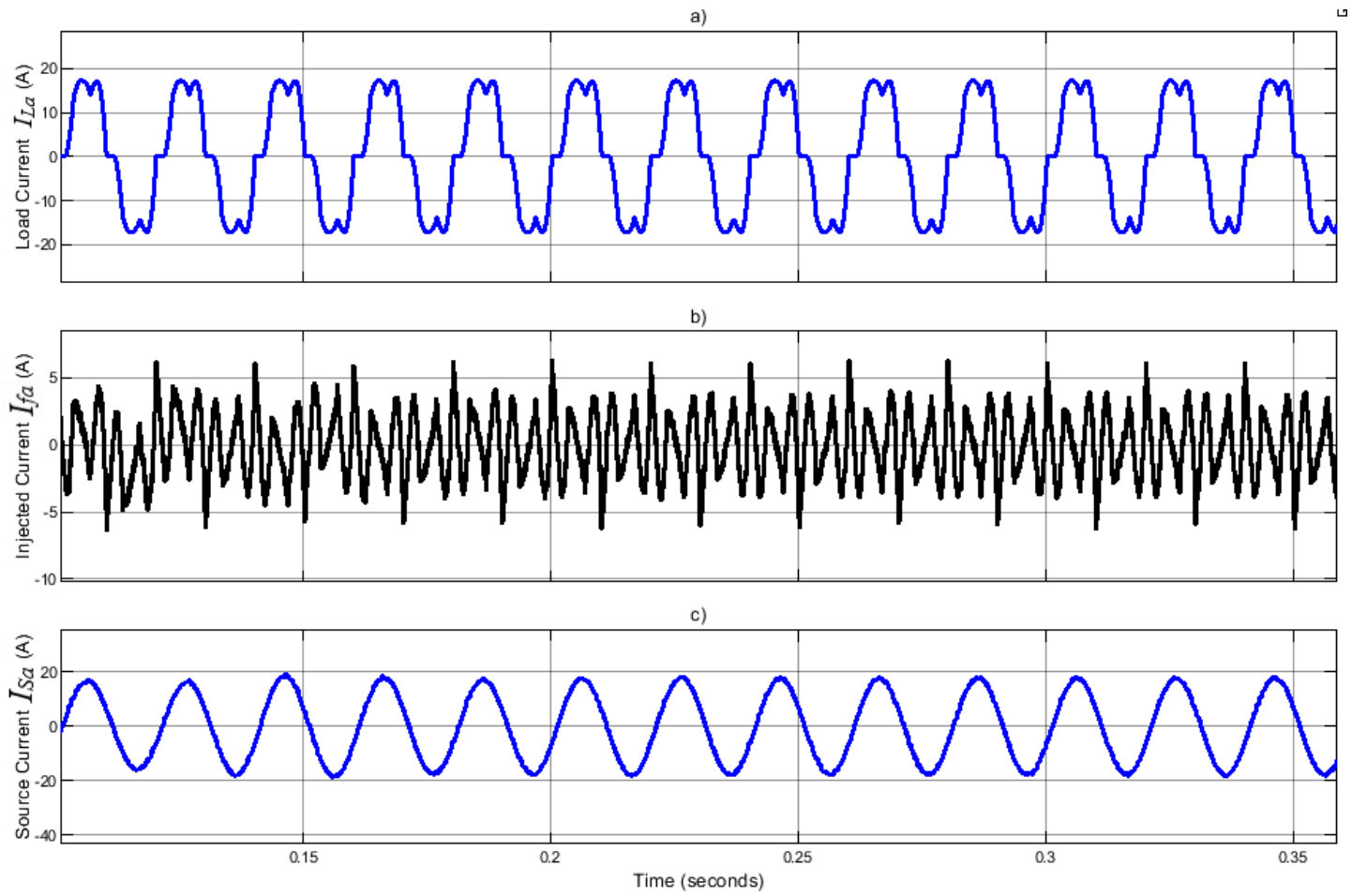

Figure 7: Phase A - a) Load current $\left.\left(I_{L a}\right)-b\right)$ Iniected Filter Current $\left.\left(I_{f a}\right)-c\right)$ Source Current

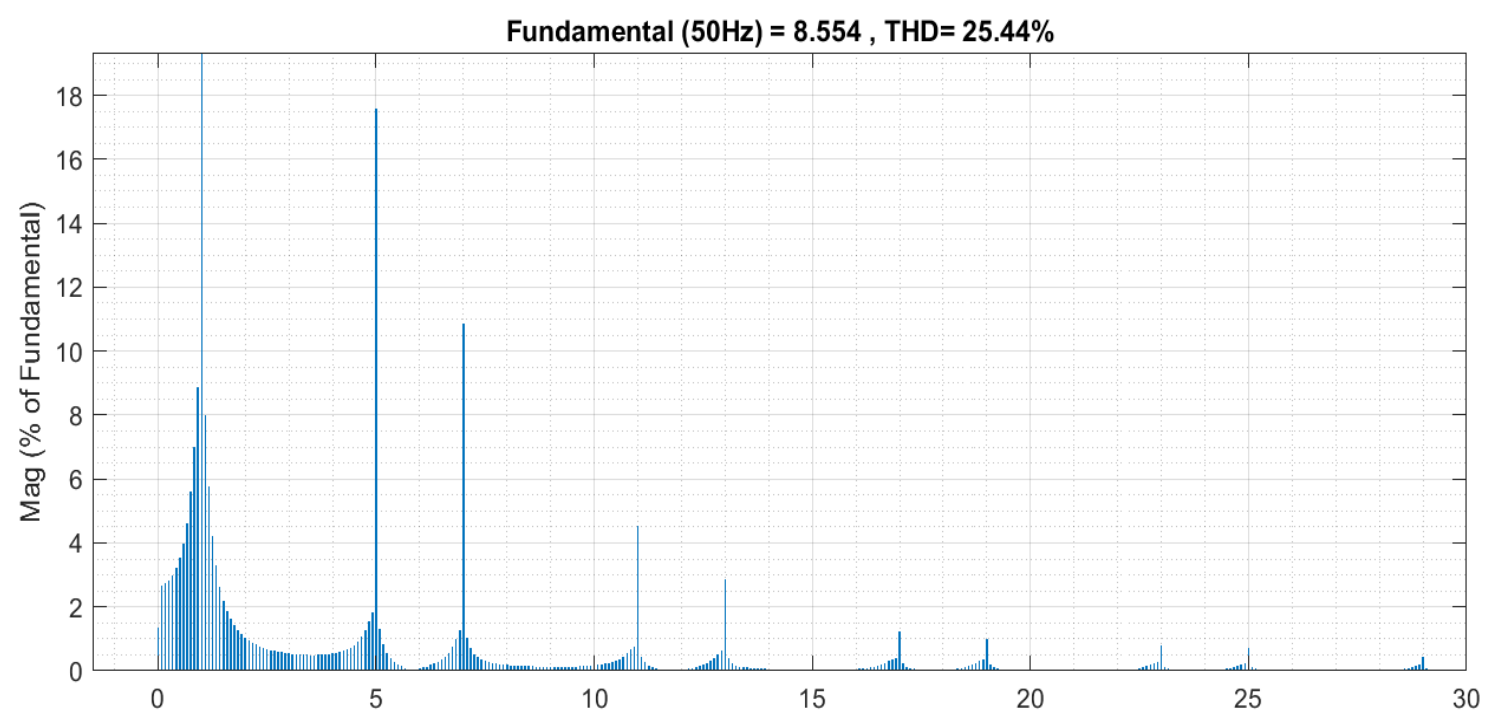

Figure 8: \% THD without SAPF 
$4^{\text {th }}$ International Conference on Modern Research in Science, Engineering and Technology

5-7 MARCH 2021

BERLIN, GERMANY

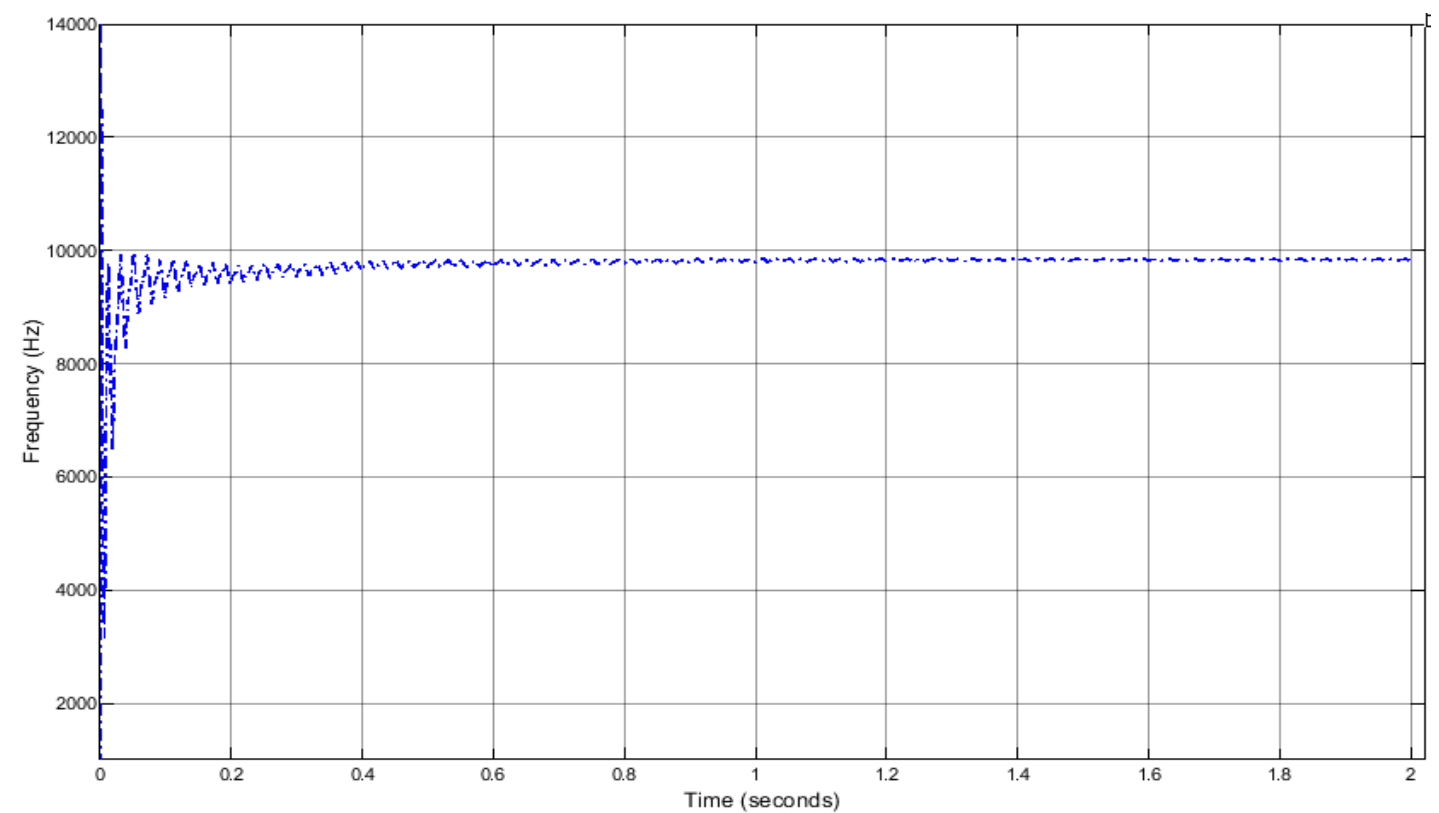

(a)

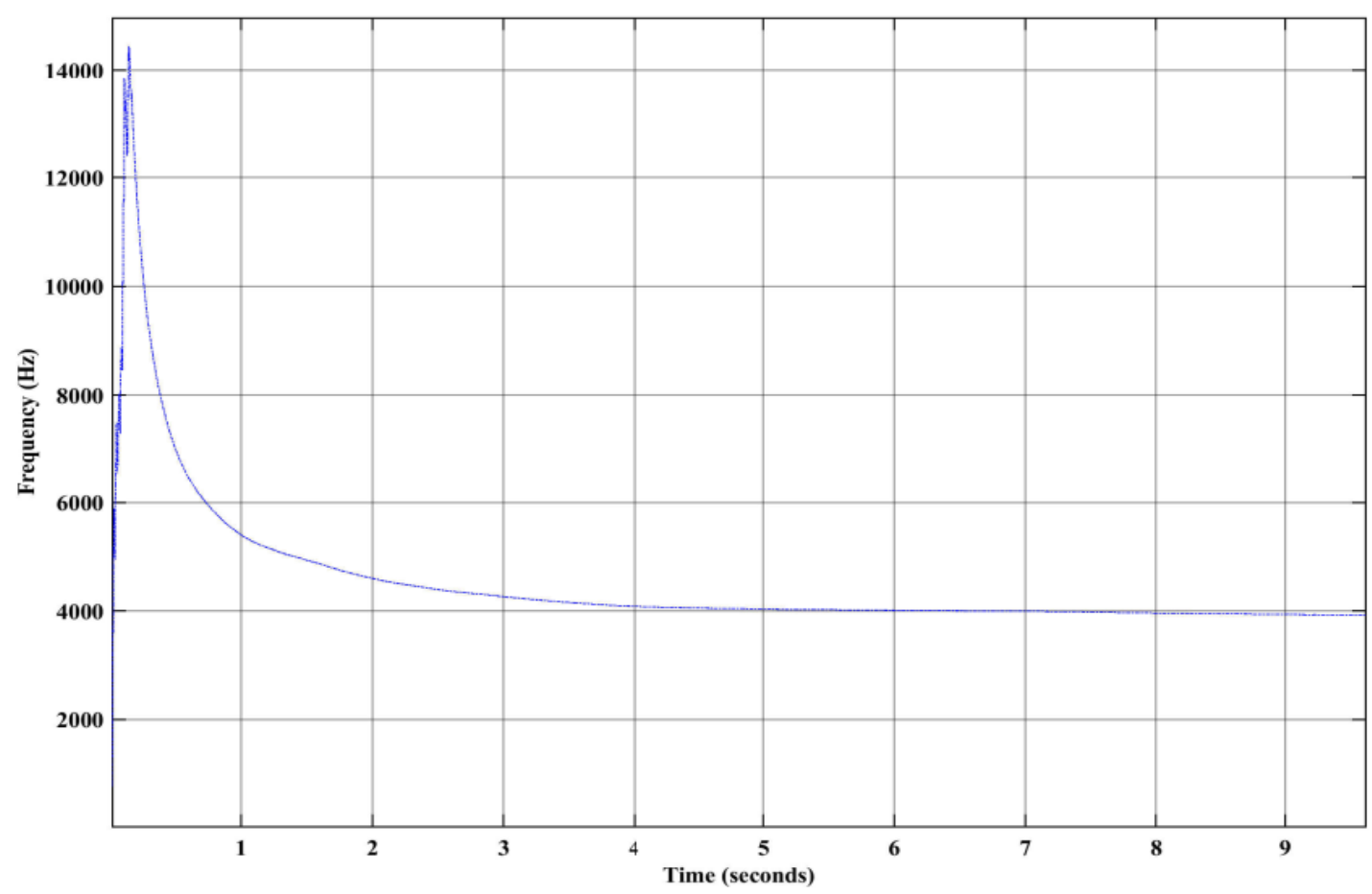

(b)

Figure 9 (a) Switching frequency before applying Adaptive Switching $(50 \mathrm{~Hz})$

(b) Switching frequency after applying Adaptive Switching $(50 \mathrm{~Hz})$ 
$4^{\text {th }}$ International Conference on Modern Research in Science, Engineering and Technology

5-7 MARCH 2021

BERLIN, GERMANY

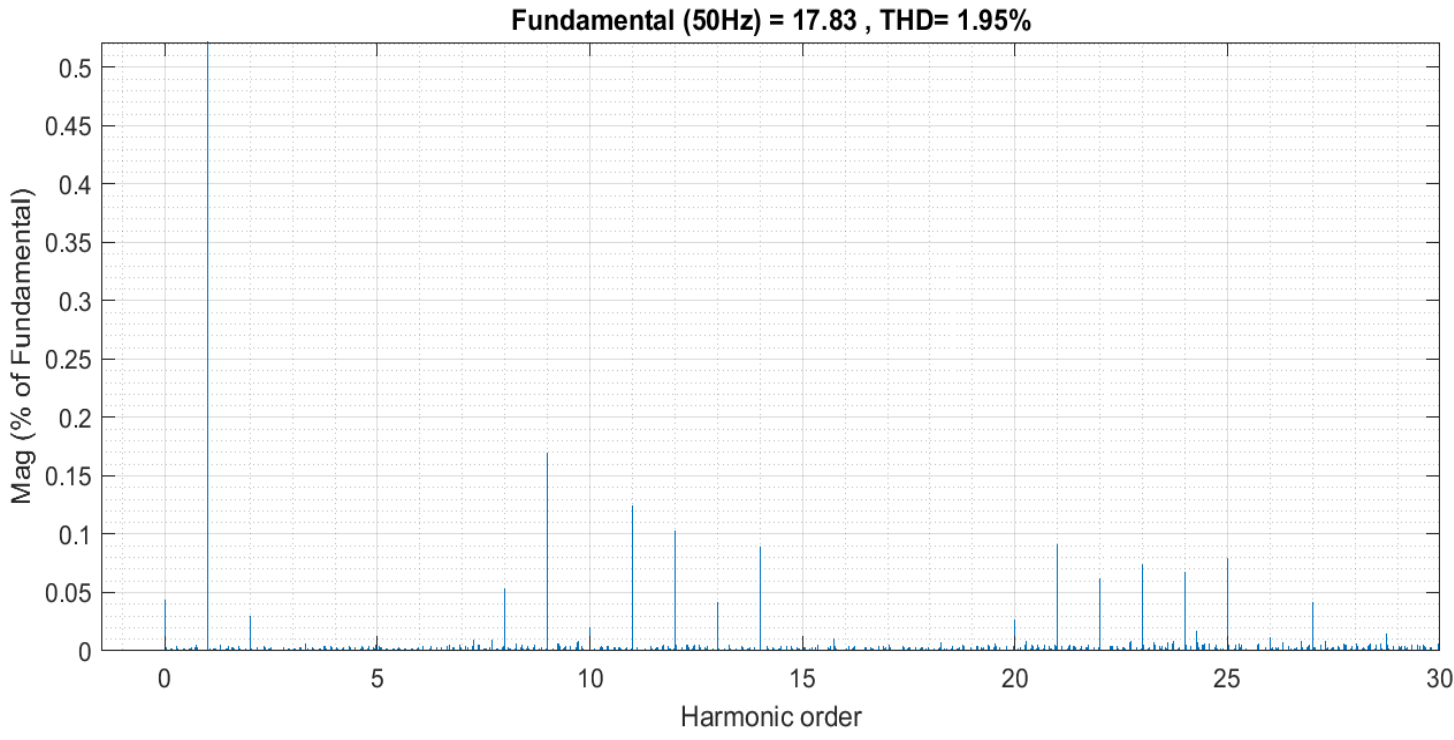

(a)

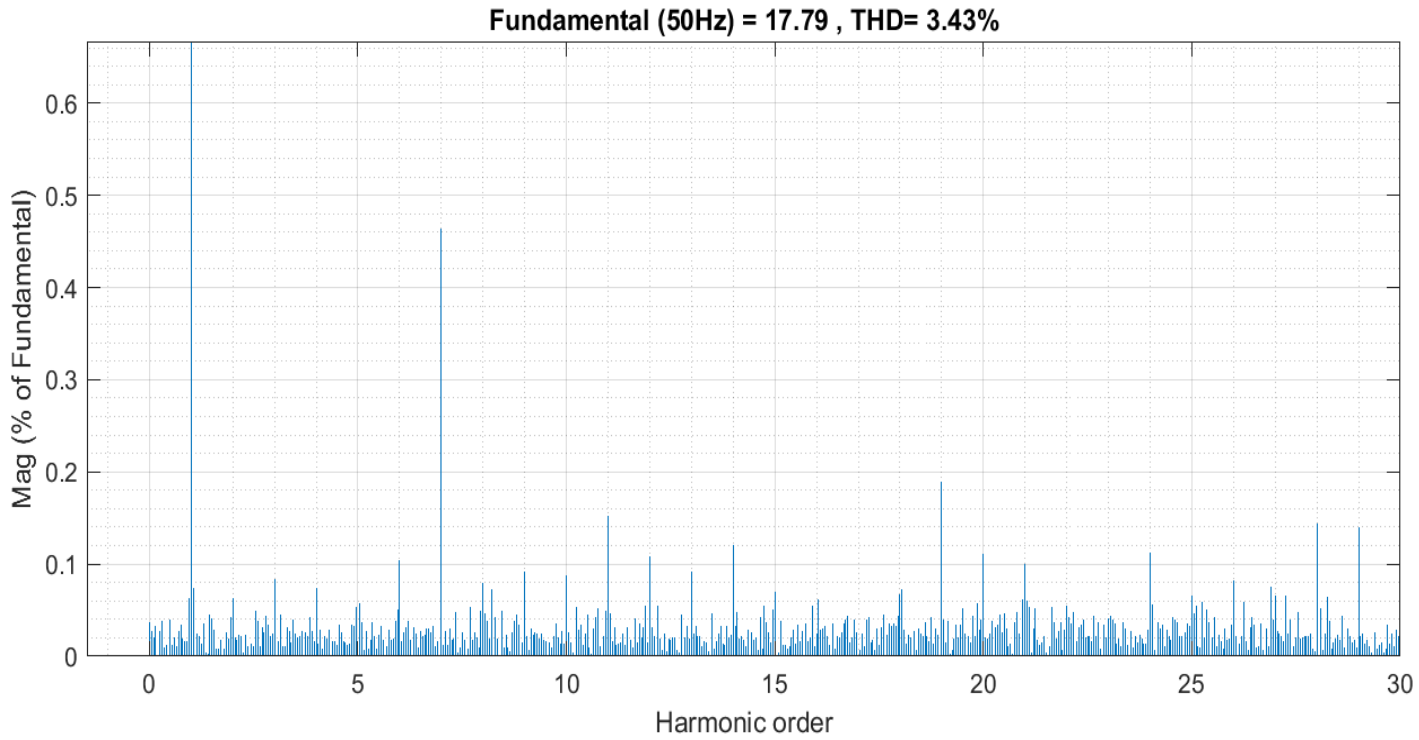

(b)

Figure 10: (a) \% THD before applying adaptive switching $\left(f_{l}=50 \mathrm{~Hz}\right)$

(b) \% THD after applying adaptive switching $\left(f_{l}=50 \mathrm{~Hz}\right)$ 
$4^{\text {th }}$ International Conference on Modern Research in Science, Engineering and Technology

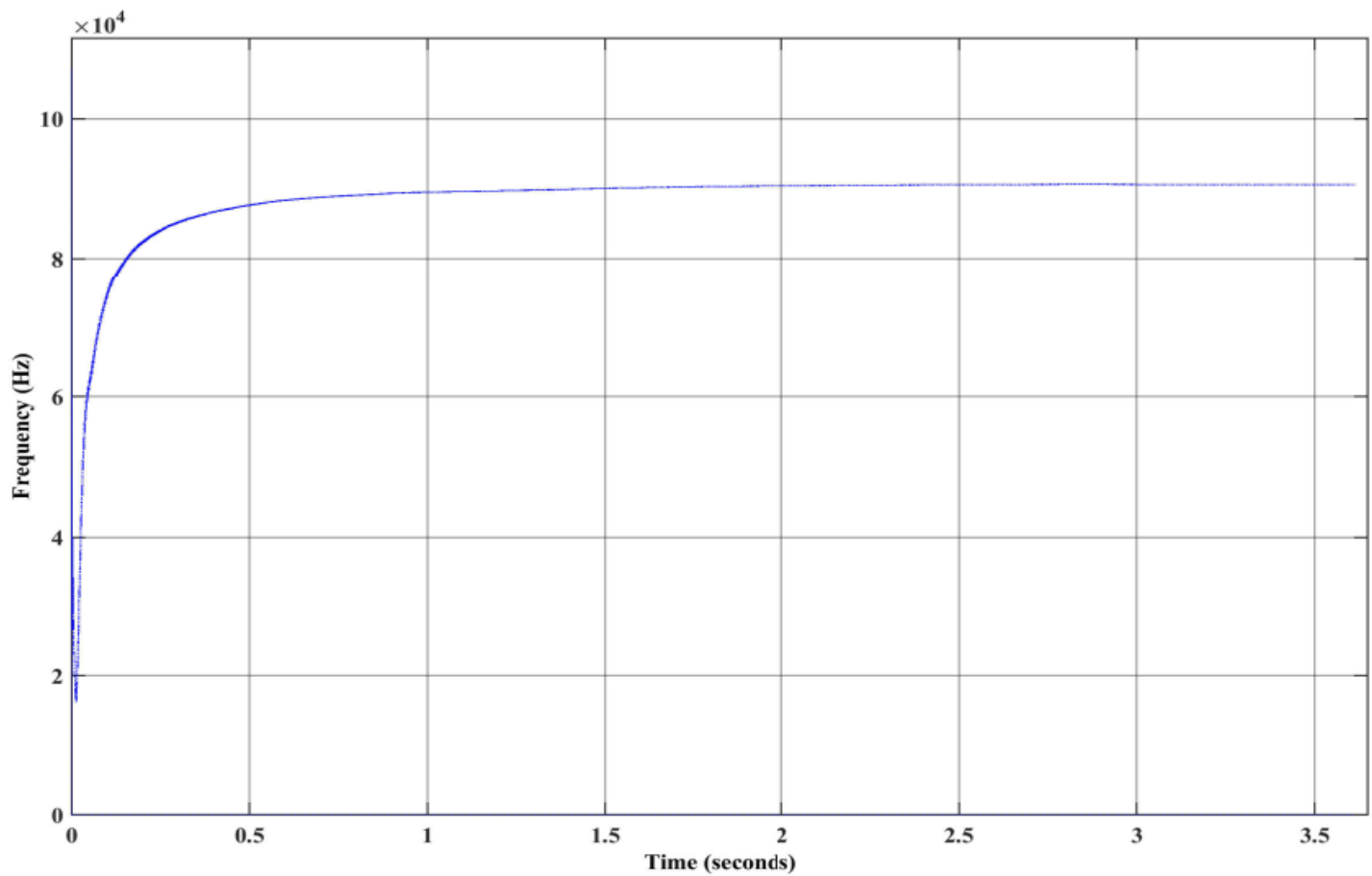

(a)

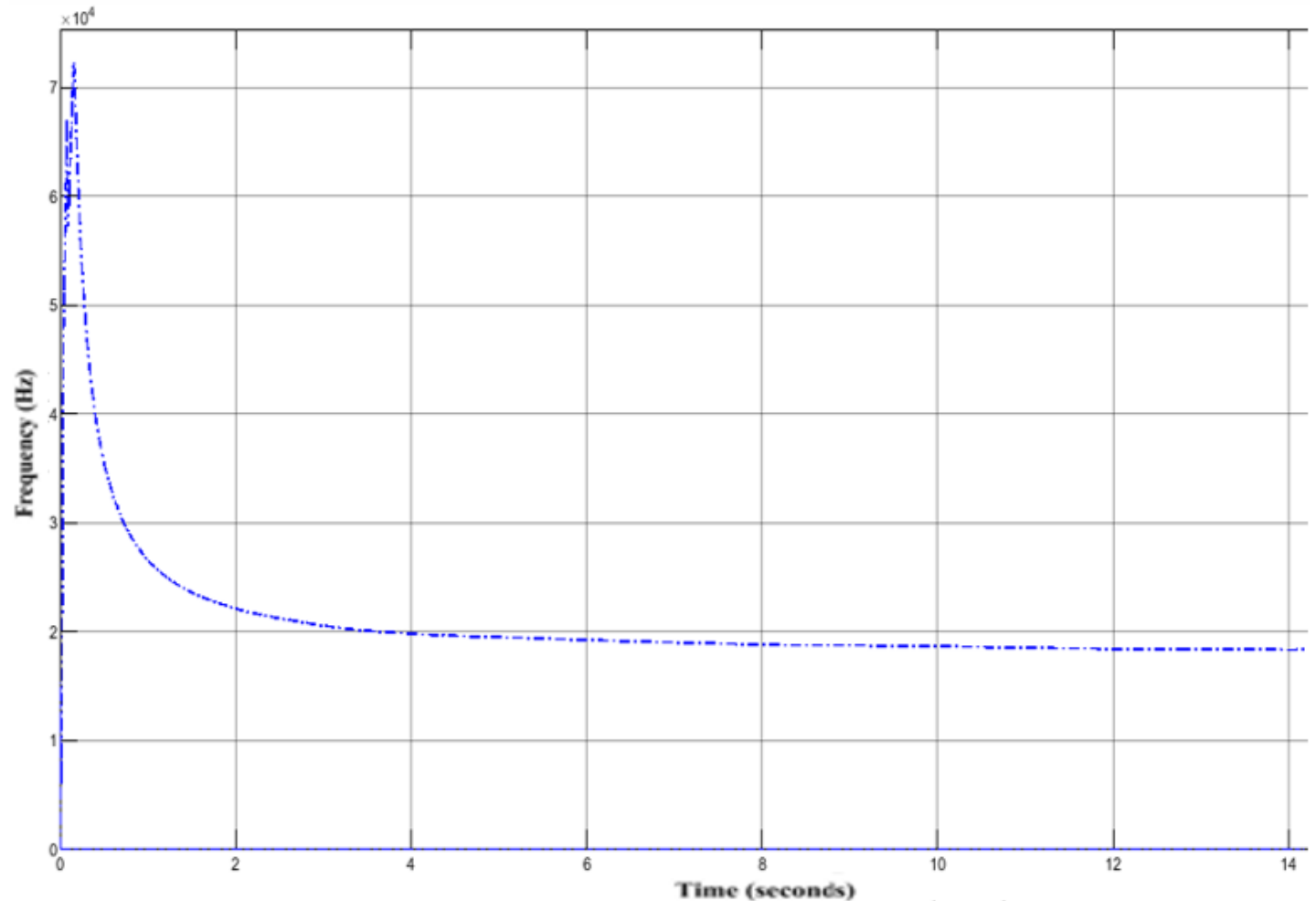

(b)

Figure 11: (a) Switching frequency before applying Adaptive Switching for Fundamental Freq (40OHz) (b) Switching frequency after applying Adaptive Switching for Fundamental Freq $(400 \mathrm{~Hz})$ 
$4^{\text {th }}$ International Conference on Modern Research in Science, Engineering and Technology

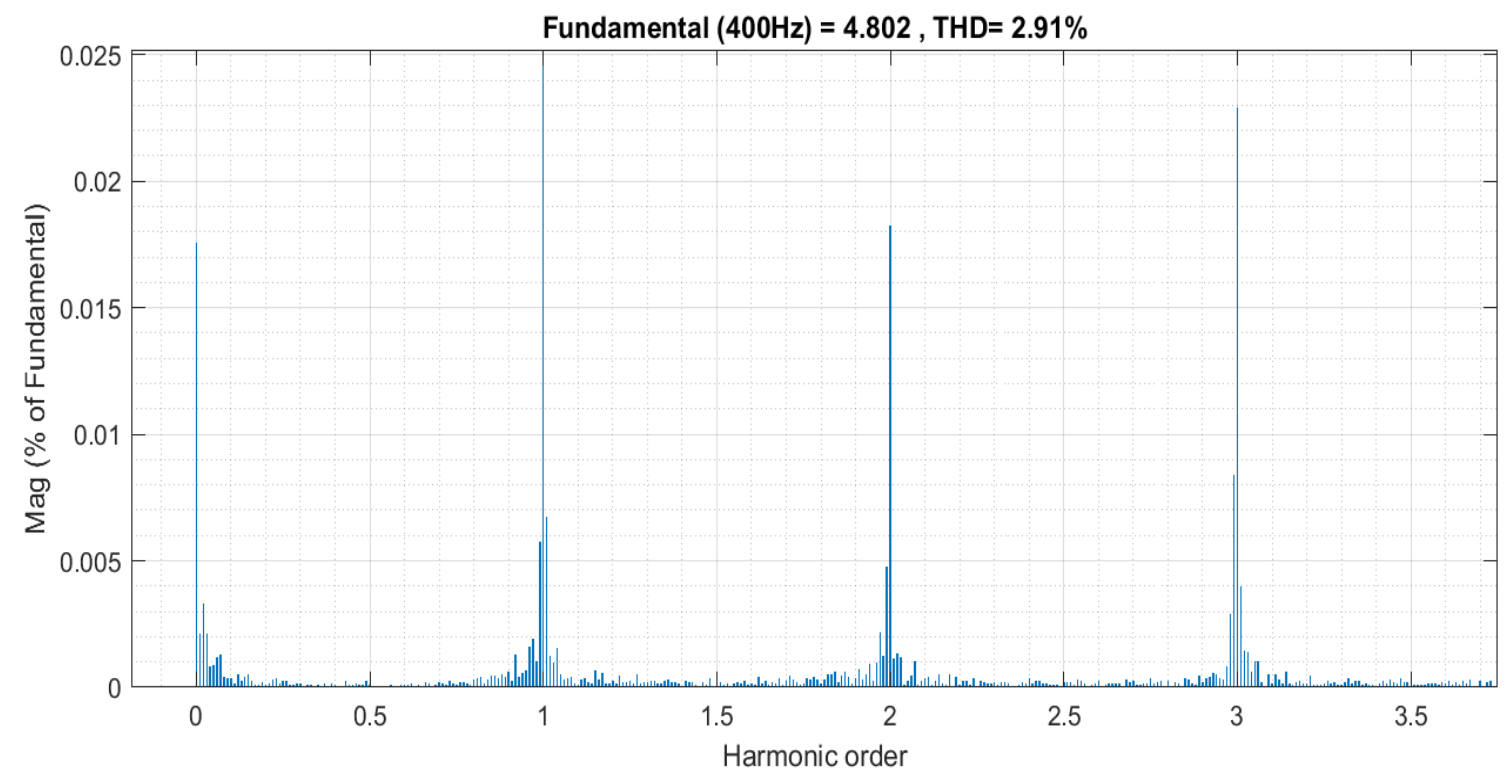

(a)

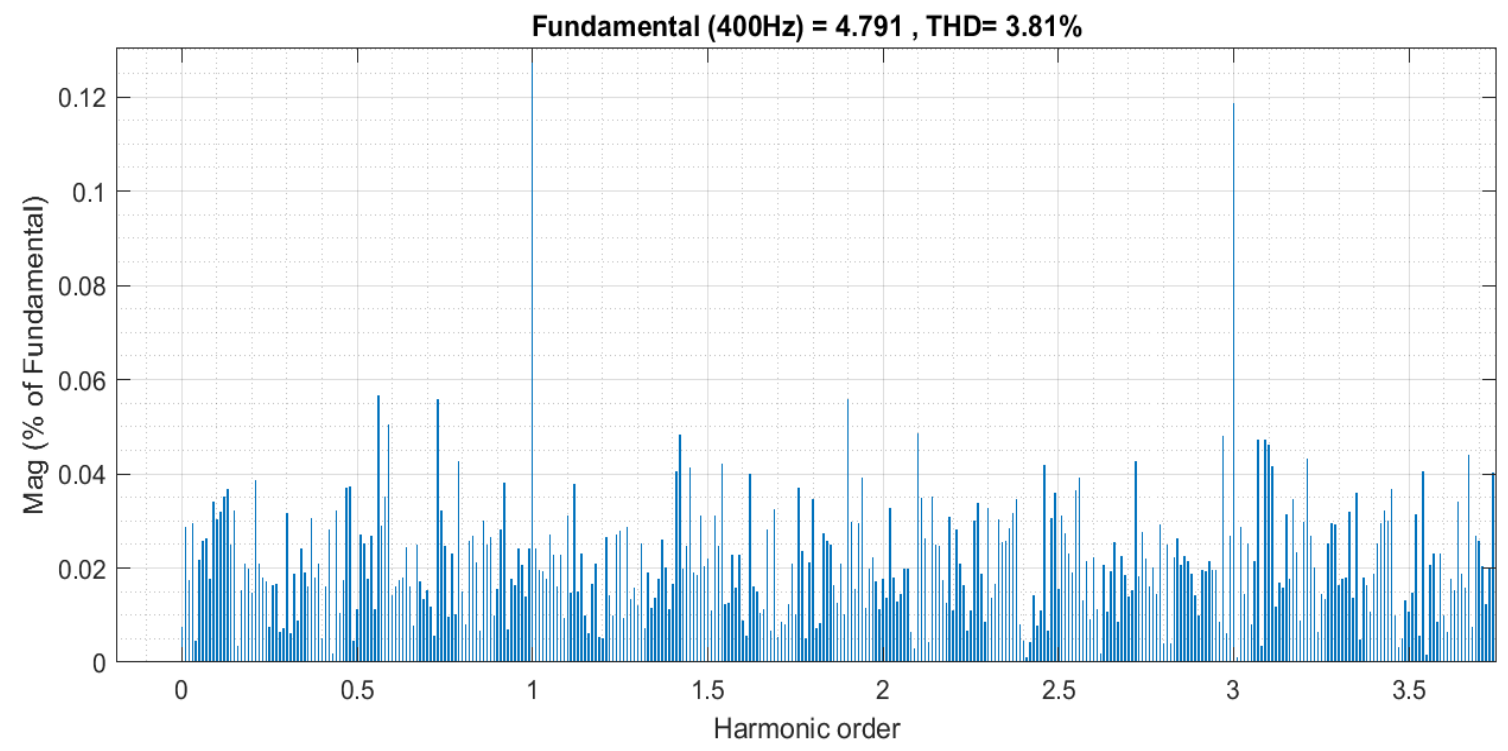

(b)

Figure 12: (a) \% THD before applying adaptive switching $\left(f_{1}=400 \mathrm{~Hz}\right)$

(b) \% THD after applying adaptive switching $\left(f_{l}=400 \mathrm{~Hz}\right)$ 


\section{Conclusion}

The results are complying with IEEE standard $519-2014(<5 \%)$. Adaptive switching supported algorithmic control to impose switching limits for power converters. Many papers and research worked on designing the optimum SAPF, others developed SAPF to work with algorithmic control substituting PI and PWM but less work concerned about the switching frequency of power converters. Applications of algorithmic control on power electronics are facing problems regarding limiting and controlling switching frequency, in the absence of PWM, within the desired limits while maintaining the main system performance.

This work shows a coherence and robust control technique between model predictive control and adaptive control to maintain the performance of the controller by imposing additional constraint to the system to increase the reliability, by free-choosing constraint limit, in addition to robustness, by having an independent adaptive control system for controlling and limiting the switching frequency.

In this paper0, Adaptive control is used, utilizing the advantages of learning factor and iteration, to add an adaptive weight factor for the model predictive control cost function. This technique represents outstanding cooperation between adaptive and model predictive control systems to maintain system stability. This technique can be applied to a wide range of algorithmic control applications with power converters.

Adaptive switching decreased the ripples of the output signal, increased the stability of the output, and promoted the protection and integrity of the power converter. 


\section{$4^{\text {th }}$ International Conference on Modern Research in Science, Engineering and Technology}

\section{References}

[1] G. Bakaoukas, K. Chao and W. Li, "Pulse Width Modulation (PWM) Method for Power Components Estimation - Active and Reactive Power Measurement," 2013 IEEE International Conference on Systems, Man, and Cybernetics, Manchester, UK, 2013, pp. 1040-1045, doi: 10.1109/SMC.2013.181.

[2] S. Bhattacharya, D. Mascarella, G. Joos and G. Moschopoulos, "Reduced switching random PWM technique for two-level inverters," 2015 IEEE Energy Conversion Congress and Exposition (ECCE), Montreal, QC, Canada, 2015, pp. 695-702, doi: 10.1109/ECCE.2015.7309757.

[3] L. Schwager, A. Tüysüz, C. Zwyssig and J. W. Kolar, "Modeling and Comparison of Machine and Converter Losses for PWM and PAM in High-Speed Drives," in IEEE Transactions on Industry Applications, vol. 50, no. 2, pp. 995-1006, March-April 2014, doi: 10.1109/TIA.2013.2272711.

[4] Jadhav, P. P., \& Patil, A. S. (2016). Reduce harmonics using PI controller in d-q reference frame for active power filter. 2016 International Conference on Global Trends in Signal Processing, Information Computing and Communication (ICGTSPICC). DOI: 10.1109/icgtspicc.2016.7955382

[5] Kalaignan, T. P., \& Raja, T. S. R. (2010). Harmonic elimination by Shunt active filter using PI controller. 2010 IEEE International Conference on Computational Intelligence and Computing Research. DOI: 10.1109/iccic.2010.5705800

[6] V, P., D, G., \& Hajira, B. (2014). Harmonic Reduction Using Shunt Active Power Filter With Pi Controller. International Journal of Scientific Engineering and Research (IJSER), 2(4), 1-6. Retrieved from https://www.ijser.in/archives/v2i4/SjIwMTMyNTE=.pdf

[7] Vlasenko, R. V., M Kobeliatskiy, A. B. B., \& Yakimets, S. N. (2016). THREE-PHASE PARALLEL ACTIVE POWER FILTER SYSTEM PRE-CHARGE CAPACITOR. International Transactions in Operational Research, 1-7. Retrieved from http://www.kdu.edu.ua/PUBL/statti/2016_6_28-34_6-2016.pdf

[8] Wu, F.-Z., Peng, S., \& Wang, B.-B. (2012). The Study on DC Capacitor Parameter Determination in Active Power Filter. Physics Procedia, 24, 496-502. DOI: 10.1016/j.phpro.2012.02.072

[9] Budhrani, A. H., Bhayani, K. J., \& Pathak, A. R. (n.d.). DESIGN PARAMETERS OF SHUNT ACTIVE FILTER FOR HARMONICS CURRENT MITIGATION. PDPU Journal of Energy \& Management, 1-7. Retrieved from http://www.pdpu.ac.in/downloads/PDPU JEM May 2018 Chapter5.pdf

[10] M. (2013).Microsemi Corporation

[11] ElHelbawy, A. (October 2019). Model predictive control with adaptive control for three phase shunt active power filter, MSc. Politecnico di Milano. Available: http://hdl.handle.net/10589/149969

[12] Widrow, B. \& Winter, Rodney. (1988). Neural Nets for Adaptive Filtering and Adaptive Pattern Recognition. Computer. 21. 25 - 39. 10.1109/2.29. 
[13] 1. Sunitha M, Kartheek BN. Elimination of Harmonics Using Active Power Filter Based on DQ Reference Frame Theory. 2013;4(April):781-785.

[14] M. Odavic, V. Biagini, M. Sumner, P. Zanchetta and M. Degano, "Low CarrierFundamental Frequency Ratio PWM for Multilevel Active Shunt Power Filters for Aerospace Applications," in IEEE Transactions on Industry Applications, vol. 49, no. 1, pp. 159-167, Jan.-Feb. 2013, doi: 10.1109/TIA.2012.2229253.

[15] K.A.-H. Bhim Singh, Ambrish Chandra, Power Quality: Problems and Mitigation Techniques, Willey, 2014.

[16] Kumar R, Bansal HO. Hardware in the loop implementation of wavelet based strategy in shunt active power fi lter to mitigate power quality issues. 2019;169(June 2018):92-104.

[17] Vazquez S, Leon JI, Franquelo LG, et al. Model predictive control: A review of its applications in power electronics. IEEE Ind Electron Mag. 2014;8(1):16-31. doi:10.1109/MIE.2013.2290138

[18] He Z, Guo P, Shuai Z, Xu Q, Luo A, Guerrero JM. Modulated Model Predictive Control for Modular Multilevel AC/AC Converter. IEEE Trans Power Electron. 2019;34(10):10359-10372. doi:10.1109/TPEL.2019.2895224

[19] Mahmoudi H, Aleenejad M, Ahmadi R. Modulated model predictive control of modular multilevel converters in VSC-HVDC systems. IEEE Trans Power Deliv. 2018;33(5):21152124. doi:10.1109/TPWRD.2017.2727478

[20] S. Kubera, R. Alvarez and J. Dorn, "Control of switching frequency for modular multilevel converters by a variable hysteresis band modulation," 2016 18th European Conference on Power Electronics and Applications (EPE'16 ECCE Europe), Karlsruhe, 2016, pp. 1-7, doi: 10.1109/EPE.2016.7695697.

[21] Zhong Chen and Miao Chen, "A novel $400 \mathrm{~Hz}$ shunt active power filter for aircraft electrical power system," Proceedings of The 7th International Power Electronics and Motion Control Conference, Harbin, China, 2012, pp. 2838-2843, doi: 10.1109/IPEMC.2012.6259316. 